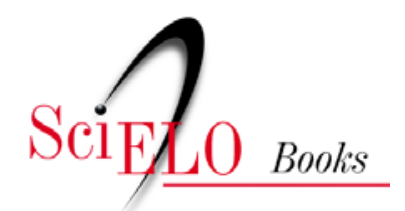

\title{
Capítulo 7 - A importância da formação continuada para ampliar os conhecimentos dos professores do Atendimento Educacional Especializado em Comunicação Alternativa e Ampliada
}

\author{
Cláudia Miharu Togashi \\ Thatyana Machado Silva \\ Carolina Rizzotto Schirmer
}

\section{SciELO Books / SciELO Livros / SciELO Libros}

TOGASHI, C. M., SILVA, T. M., and SCHIRMER, C. R. A importância da formação continuada para ampliar os conhecimentos dos professores do Atendimento Educacional Especializado em Comunicação Alternativa e Ampliada. In: NUNES, L. R. O. P., and SCHIRMER, C. R., orgs. Salas abertas: formação de professores e práticas pedagógicas em comunicação alternativa e ampliada nas salas de recurso multifuncionais [online]. Rio de Janeiro: EDUERJ, 2017, pp. 169-176. ISBN: 97885-7511-452-0. Available from: doi: 10.7476/9788575114520.009. Also available in ePUB from: http://books.scielo.org/id/xns62/epub/nunes-9788575114520.epub.

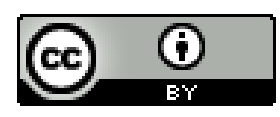

All the contents of this work, except where otherwise noted, is licensed under a Creative Commons Attribution 4.0 International license.

Todo o conteúdo deste trabalho, exceto quando houver ressalva, é publicado sob a licença Creative Commons Atribição 4.0.

Todo el contenido de esta obra, excepto donde se indique lo contrario, está bajo licencia de la licencia $\underline{\text { Creative Commons }}$ $\underline{\text { Reconocimento 4.0. }}$ 


\section{Capítulo 7 - A importância da formação continuada para ampliar os conhecimentos dos professores do Atendimento Educacional Especializado em Comunicação Alternativa e Ampliada}

Cláudia Miharu Togashi ${ }^{1}$

Thatyana Machado Silva ${ }^{2}$ Carolina Rizzotto Schirmer ${ }^{3}$

\section{Introdução}

Aprimorar a teoria e propor novas técnicas são importantes para a renovação dos conhecimentos de todo profissional. No caso dos profissionais da área da Educação, isso também se torna necessário a fim de aprimorar a

1 Doutoranda em Educação pelo Programa de Pós-Graduação em Educação da UERJ. Secretaria Municipal de Educação do Rio de Janeiro. E-mail: claudiatogashi@yahoo.com. br.

2 Mestre em Educação pelo Programa de Pós-Graduação em Educação da UERJ. Secretaria Municipal de Educação de Rio das Ostras. E-mail: thatyana.ms@gmail.com.

3 Professora adjunta da Faculdade de Educação da UERJ. E-mail: ead.carolina@gmail. com. 
prática pedagógica. Nesse sentido, a formação continuada em serviço é fundamental para que o professor se torne cada vez mais habilitado e seguro e, dessa forma, possa desenvolver a profissão docente.

Os desafios para lidar com os alunos que são público-alvo da Educação Especial são muitos no processo de inclusão escolar e vão desde a peculiaridade presente em cada indivíduo até as práticas pedagógicas necessárias para desenvolver-se juntamente com os alunos da classe regular. Daí a importância de estudar e buscar frequentemente novas práticas e saberes para conseguir atender às demandas desse alunado.

Especificamente quando falamos de indivíduos com Transtorno do Espectro do Autismo (TEA), verifica-se uma grande dificuldade para trabalhar no contexto escolar, por conta da natureza e da gravidade do transtorno (Simpson et al., 2004), em que o prejuízo na interação social acarreta deficiências na comunicação verbal e não verbal, limitação das atividades e interesses, além de padrões de estereotipias no comportamento (Zilbovicius et al., 2006).

Entre tantos outros importantes fatores que devem ser trabalhados e desenvolvidos em indivíduos com TEA, a comunicação é fundamental e necessária para favorecer seu processo de inclusão (Togashi, 2014). Portanto, o uso de recursos da Comunicação Alternativa e Ampliada (CAA) torna-se um forte aliado como instrumento para incrementar a interação entre o aluno com TEA e seus interlocutores.

O presente trabalho é um relato de experiência gerado a partir da minha participação como sujeito de uma pesquisa de mestrado de autoria de Thatyane Machado Silva, cuja proposta foi a formação continuada para professores do Atendimento Educacional Especializado (AEE) do município do Rio de Janeiro, tendo a autoscopia como um instrumento para avaliação e análise da prática pedagógica.

Para Sadalla e Laroca (2004), a autoscopia é um recurso de videogravação de uma prática, cujo objetivo é a autoavaliação por um ou mais protagonistas dessa prática, apreendendo, assim, as açōes do ator, o cenário e a trama que compõem uma situação. Como passos para a realização do procedimento de autoscopia, os referidos autores sinalizam que o material filmado "é submetido a sessões de análise a posteriori da ação, as quais se destinam à apreensão do processo reflexivo do ator (ou atores), através de suas verbalizações durante a análise das cenas videogravadas" (p. 421). Sendo assim, as 
sessões de formação continuada envolveram os procedimentos citados anteriormente, a fim de fomentar as discussões com a pesquisadora e a professora que foi sujeito da pesquisa.

\section{Objetivo}

Descrever as contribuições da autoscopia como ferramenta na formação continuada da professora de Atendimento Educacional Especializado, favorecendo o uso dos recursos da Comunicação Alternativa e Ampliada com o aluno com TEA.

\section{Método}

Participantes: a) $\mathrm{Célia}^{4}$, professora do AEE, com 30 anos de idade. Atuava no magistério há seis anos, sendo quatro desses atuando como AEE; b) Arthur ${ }^{5}$, aluno do $3 .^{\circ}$ ano do ensino fundamental, diagnosticado com TEA, sem fala articulada, apenas vocalizava alguns sons. Gritava muito em diversas situaçóes quando era contrariado, sendo agressivo com os seus interlocutores, e apresentava movimentos estereotipados quando estava ansioso e agitado.

Locais: as sessões de atuação da prática pedagógica de Célia com Arthur ocorreram na Sala de Recursos da professora Célia, em uma escola municipal da zona norte do Rio de Janeiro. As sessões de autoscopia para a formação continuada aconteceram no Instituto Helena Antipoff e no Laboratório de Tecnologia Assistiva da Universidade do Estado do Rio de Janeiro.

4 Nome fictício da autora do presente capítulo.

5 Nome fictício. 
Materiais utilizados: para registrar as sessões na Sala de Recursos, era usada a câmera digital do aparelho celular da professora de AEE. Além disso, também foram usados cartões de comunicação alternativa e diversos materiais pedagógicos adaptados para os atendimentos com o aluno Arthur e o PEI (Plano Educacional Individualizado), cujo modelo foi proposto pela SME/RJ.

Procedimentos gerais: envio do projeto ao comitê de ética e sua aprovação, no processo n. ${ }^{\circ}$ 336.622, de 11/07/2013, do COEP (UERJ) e preenchimento do Termo de Consentimento Livre e Esclarecido da professora participante e da responsável legal pelo aluno.

Procedimentos específicos: a professora Célia filmava as sessões de atendimento com o seu aluno na Sala de Recursos e enviava as filmagens para a pesquisadora analisá-las previamente. A escolha para que o registro em vídeo fosse realizado pela própria professora levou em consideração o possível estranhamento do aluno se a sessão fosse filmada por uma pessoa diferente na sala de aula. As sessões tinham em torno de trinta minutos de duração, dentre os quais a pesquisadora selecionava cenas que evidenciassem as seguintes categorias: 1) professora favorece a comunicação do aluno; 2) aluno se comunica com a professora; 3) aluno faz uso de diferentes funçóes comunicativas; 4) desempenho acadêmico do aluno; e 5) prática pedagógica do profissional. Posteriormente, os vídeos eram apresentados à professora Célia para a realização da sessão de autoscopia. Ao todo, foram praticadas sete sessões em que a professora assistia às cenas selecionadas e, logo após, era convidada a refletir e comentar sobre seus sentimentos e impressões ao ver o modo como conduzia sua prática pedagógica. Ao terminar o processo de autoavaliação da professora, a pesquisadora fazia os seus comentários e dava contribuições, possibilitando que Célia atentasse para os comportamentos e interesses de Arthur, que, até então, passavam despercebidos na correria do cotidiano escolar. 


\section{Resultados}

Por meio do procedimento de autoscopia, a professora Célia percebeu que era necessário mudar a sua prática pedagógica. A partir da percepção que teve da sua atuação, ela reconheceu a importância de utilizar mais os recursos da Comunicação Alternativa e Ampliada para que seu aluno tivesse condições de se comunicar e se expressar de modo autônomo. Isso afetou diretamente o comportamento e a relação que ela mantinha com Arthur.

A seguir, há um quadro que sinaliza alguns exemplos das mudanças pontuadas pela professora ao longo das sessóes de autoscopia:

\begin{tabular}{|l|l|l|}
\hline Situação & Sessōes iniciais & Sessões após a autoscopia \\
\hline $\begin{array}{l}\text { Organização da roti- } \\
\text { na do atendimento na } \\
\text { sala de recursos }\end{array}$ & $\begin{array}{l}\text { A professora usava cartões de CAA, } \\
\text { mas o aluno pegava e jogava no chão } \\
\text { ou tentava rasgar. }\end{array}$ & $\begin{array}{l}\text { A professora continuou fa- } \\
\text { zendo uso dos cartóes, e o } \\
\text { aluno começou a aceitá-los e } \\
\text { a entender sua função social. }\end{array}$ \\
\hline $\begin{array}{l}\text { Solicitação de algo } \\
\text { para o aluno, como } \\
\text { sentar-se à mesa para } \\
\text { a realização da ati- } \\
\text { vidade }\end{array}$ & $\begin{array}{l}\text { A professora ficava sentada à mesa, } \\
\text { chamando o aluno, sem ser atendi- } \\
\text { de costas para ele. }\end{array}$ & $\begin{array}{l}\text { A professora deslocava-se para } \\
\text { perto do aluno, abaixava-se e } \\
\text { usava o cartão de sentar para } \\
\text { se fazer entendida por ele. }\end{array}$ \\
\hline $\begin{array}{l}\text { Propostas de ativida- } \\
\text { des pedagógicas }\end{array}$ & $\begin{array}{l}\text { A professora realizava atividades } \\
\text { pouco atrativas e sem funcionalidade } \\
\text { para o aluno. }\end{array}$ & $\begin{array}{l}\text { A professora co meçou a } \\
\text { desenvolver atividades que } \\
\text { pudessem ser utilizadas no } \\
\text { cotidiano do aluno, dando } \\
\text { mais funcionalidade ao que } \\
\text { era proposto. }\end{array}$ \\
\hline $\begin{array}{l}\text { Agressividade do alu- } \\
\text { no }\end{array}$ & $\begin{array}{l}\text { O aluno era muito agressivo quando } \\
\text { contrariado. Por diversas vezes, a a } \\
\text { professora ficava com hematomas } \\
\text { nos braços. }\end{array}$ & $\begin{array}{l}\text { Com uso de cartões de co- } \\
\text { municação alternativa e ati- } \\
\text { vidades pedagógicas mais } \\
\text { interessantes para o aluno, } \\
\text { houve a diminuição dos com- } \\
\text { portamentos desafiadores } \\
\text { deste. Cartões com as frases } \\
\text { "Não pode bater" ou "Não } \\
\text { pode machucar" começaram } \\
\text { a ser usados. }\end{array}$ \\
\hline
\end{tabular}




\begin{tabular}{|l|l|l|}
\hline Situação & Sessões iniciais & Sessões após a autoscopia \\
\hline $\begin{array}{l}\text { Organização da sala } \\
\text { de recursos }\end{array}$ & $\begin{array}{l}\text { As mesas eram organizadas em dois } \\
\text { grupos, dificultando o acesso para } \\
\text { todos os cantos da sala e restringindo } \\
\text { o espaço para atividades mais livres. }\end{array}$ & $\begin{array}{l}\text { A sala foi reorganizada de } \\
\text { modo que houvesse maior } \\
\text { possibilidade de o aluno tran- } \\
\text { sitar por ela. Também foi } \\
\text { reservado um espaço para se- } \\
\text { rem feitas atividades lúdicas, } \\
\text { como uso da bola e do jogo } \\
\text { de boliche. }\end{array}$ \\
\hline $\begin{array}{l}\text { Uso dos recursos de } \\
\text { CAA }\end{array}$ & $\begin{array}{l}\text { A professora fazia uso da CAA com } \\
\text { o aluno, mas de forma instrutiva, } \\
\text { apenas para auxiliá-lo na organiza- } \\
\text { ção de rotina e oferta de atividades } \\
\text { pedagógicas dirigidas. Não havia o } \\
\text { objetivo de ampliar a comunicação } \\
\text { do aluno. }\end{array}$ & $\begin{array}{l}\text { O aluno passou a usar os } \\
\text { cartóes de CAA não somente } \\
\text { as organizar e realizar } \\
\text { para iniciar a comunicação } \\
\text { e responder às perguntas } \\
\text { feitas pela professora. Isso fez } \\
\text { com que os recursos de CAA } \\
\text { fossem usados para estabele- } \\
\text { cer uma comunicação mais } \\
\text { efetiva. }\end{array}$ \\
\hline
\end{tabular}

\section{Discussão}

A partir do quadro apresentado anteriormente, verifica-se a mudança na postura e no comportamento de ambos os participantes. Tanto a professora quanto o aluno tiveram ganhos, a partir da nova prática da professora Célia e das novas formas de comunicar e intereagir de Athur, que passou a se beneficiar do uso mais expressivo da comunicação alternativa e ampliada.

A formação continuada é um dos fatores que contribuem para a garantia do sucesso profissional e, principalmente, dos alunos no ambiente escolar. Além da formação continuada, ressalte-se ainda que esta pode estar aliada ao desejo do professor de querer desenvolver um trabalho pedagógico de qualidade, uma vez que a capacitação visa a oferecer novos conhecimentos, atualizações de conceitos e sugestóes de práticas cotidianas no contexto escolar.

Schirmer et al. (2011) defendem a importância da formação continuada como uma meta para todos os educadores, como forma de comprometimento profissional, a fim de oferecer educação de qualidade em todos os níveis de 
ensino. Para essas autoras, um professor que se atualiza e se informa constantemente, buscando formas novas na atuação pedagógica e acreditando no potencial dos seus alunos, terá maior satisfação, além de alcançar sucesso profissional.

Além disso, a autoscopia como uma ferramenta capaz de sensibilizar e auxiliar o professor em sua atuação de modo crítico e na construção da sua percepção e do seu conhecimento (Silva, 2016) foi de grande valia, constituindo um instrumento para a formação continuada do professor. Silva (2016) ressalta que essa técnica permite que "o professor consiga se observar com o distanciamento necessário para refletir sobre suas posturas e (re)formular suas práticas no modo de ensinar e planejar suas aulas" (p. 27).

A comunicação é imprescindível para o desenvolvimento de um ser humano, logo, uma pessoa que nasce ou torna-se desprovida dessa capacidade pode sofrer grandes impactos na sua qualidade de vida (Schirmer et al., 2007). Oferecer um sistema de CAA a alunos que apresentam dificuldades em se comunicar é, portanto, possibilitar novas formas de aproximação e interação social, facilitando desde as atividades desenvolvidas na escola às questôes práticas para a vida cotidiana, na relação com outras pessoas do seu círculo de convívio.

No caso de indivíduos com autismo, tais formas alternativas à fala são fundamentais à medida que possam ser um canal de comunicação em comum, diminuindo, assim, muitos distúrbios de condutas decorrentes das dificuldades comunicativas e sendo substituídos por comportamentos comunicativos claros, eficazes e mais adequados e socialmente aceitos (Walter, 2009).

\section{Conclusão}

Os estudos apresentados neste trabalho são fundamentais na medida em que contribuem para reforçar o papel da comunicação na inclusão de indivíduos com TEA no sistema comum de ensino. Além disso, oferecer recursos e meios alternativos que possam substituir ou ampliar a forma de interagir é benéfico não somente aos usuários da CAA, como também para todos os que pertencem ao mesmo meio social.

O ponto principal deste estudo, no entanto, foi perceber que é preciso voltar o olhar para nossos alunos. É preciso estar atento ao que eles querem nos 
dizer, mesmo com a falta de palavras articuladas, pois seus gestos nos revelam inúmeras possibilidades de trabalho.

Para que o professor tenha uma prática pedagógica que seja, de fato, qualitativa para o aluno, ele precisa sair de si e ir ao encontro daquilo que seja eficaz para o discente. Isso requer mudança de atitudes, de planejamento e de perspectiva. Silva (2016) afirma que a autoscopia é como uma janela, visto que "possibilita o professor a sair de si e a olhar as coisas exteriores que estão ao seu redor, de modo que ele não seja mais o único ser do universo". Nesse sentido, viver a experiência da autoscopia e ter a oportunidade de realizar um processo de reflexão profunda sobre a própria prática foi fundamental para que a professora Célia rompesse a barreira do imediatismo e flexibilizasse seu planejamento escolar.

No início da pesquisa, a professora comportava-se de maneira ansiosa e exigia, a todo tempo, que o aluno realizasse atividades que estivessem exatamente de acordo com aquilo que ela planejou. No decorrer do estudo, ela tornou-se mais flexível e se aproximou do aluno para perceber seus interesses, suas potencialidades e suas dificuldades.

Ao olhar para si própria, a docente acabou encontrando o seu aluno. Podemos, então, dizer que o comportamento e a intenção comunicativa de Arthur estão ligados ao modo como a professora planeja e executa o seu fazer pedagógico. Quanto mais o planejamento dela fosse adequado aos interesses do aluno, mais ele se mantinha envolvido com as atividades e diminuía o seu comportamento desafiador.

Com isso, ressalta-se a importância do AEE como parte fundamental no processo de inclusão escolar, dando suporte ao aluno na Sala de Recursos e na sala de aula. É preciso que o professor do AEE trabalhe em paralelo com o professor da turma comum, mesmo com todas as dificuldades e barreiras encontradas. E, em se tratando de alunos que não apresentem comunicação verbal, é imprescindível que o professor da Sala de Recursos oriente o professor da sala comum a utilizar a CAA como um meio de promover a inclusão e a autonomia desse aluno. Somente a partir do momento em que o discente conseguir expressar seus desejos, medos e angústias é que ele vai conseguir organizar seus sentimentos e diminuir seus comportamentos desafiadores/provocativos. 